\title{
LEGISLACIÓN SOBRE EXTRANJEROS A FINALES DEL SIGLO XVIII.
}

\author{
JESUS MANUEL GONZÁLEZ BELTRÁN \\ Universidad de Cádiz
}

La presencia de extranjeros en los reinos hispánicos durante el periodo cronológico de la Edad Moderna es un elemento constante, significativo y de amplias repercusiones, no sólo demográficas, sino también sociales y económicas. Investigadores españoles (Nadal, Domínguez Ortiz, Carande, Vicens Vives, Anes,...) e hispanistas de otros países (See, Girard, Ponsot, Ozanam,...) se han ocupado en numerosas ocasiones de estudiar las colonias de extranjeros residentes en nuestro territorio, mostrando especial atención sobre aspectos tales como su número, su procedencia y las actividades económicas en las que se ocupaban. El resultado de todas estas investigaciones queda reflejado en una notable colección bibliográfica que, aunque innegablemente provechosa, no permite aún el conocimiento global del fenómeno de la inmigración foránea hacia España en los tiempos modernos, tan sólo acercamientos parciales. Así, en cuanto a la cronología, prevalecen los trabajos sobre los extranjeros en el siglo XVII (1). Del mismo modo, son las zonas catalana, aragonesa y bajoandaluza sobre las que versan más estudios (2), algo natural 'si tenemos en cuenta que en ellas se detecta una mayor presencia de extranjeros. Finalmente, no todos los inmigrantes foráneos han sido analizados con la misma intensidad, mostrándose interés, principalmente, por los franceses, en cuanto a las nacionalidades (3); y por los extranjeros dedicados al comercio, en lo que a las actividades económicas que desarrollaban se refiere.

Pensamos que durante el siglo XVIII, contrariamente a la opinión de Anes (4), el número de extranjeros residentes en España aumentó, especialmente en zonas como el Levante y las costas de Andalucía que, tradicionalmente, habían constituido focos de atracción por su dinamismo económico y tráfico mercantil. En la inmigración hacia la región andaluza ocupa un lugar destacado la bahía de Cádiz, tanto la propia capital como las localidades de su entorno (El Puerto de Santa María, Sanlúcar de Barrameda, Jerez de la Frontera, Puerto Real,...) (5). El traslado de la Casa de la Contratación y, en definitiva, la ubicación de la cabecera del monopolio comercial con Indias en la ciudad de Cádiz, en 1717, va a acentuar el papel de la bahía gaditana como lugar de destino de la inmigración foránea durante la centuria dieciochesca (6).

En el presente artículo, tomando como marco espacial de referencia la ciudad de El Puerto de Santa María, localidad ubicada en la mencionada bahía de Cádiz, vamos a exponer y analizar la legislación que, relativa a las colonias extranjeras residentes en los territorios de la monarquía hispana, se promulgó durante la última década del siglo XVIII. Este conjunto de normas, que, teóricamente, afectaba a todo extranjero residente en España, tenía como destinataria principal a la colonia francesa, puesta bajo sospecha a raíz de los 
acontecimientos políticos (Revolución, ajusticiamiento de Luis XVI, gobierno de la Convención,...) que se desarrollaban en su país de origen. En efecto, las órdenes emitidas tenían como objetivo principal, y así lo apuntan Herr y Anes, contener la actividad propagandística revolucionaria de los franceses dentro del territorio español (7).

\section{LA MATRICULA DE 1791.}

La Revolución francesa tuvo desde su inicio amplia resonancia en España, al menos en los ámbitos políticos de la Corte. Se temía un posible contagio del fervor revolucionario al territorio español, por lo que inmediatamente se empezaron a tomar medidas para evitar la entrada de cualquier tipo de propaganda subversiva y la divulgación de noticias sobre los sucesos que ocurrían en Francia. Esta labor de vigilancia y control se ejecutó paralelamente por las autoridades civiles y la Inquisición, la cual gracias a estas nuevas competencias se revitaliza y recupera un poder que durante los últimos decenios había ido perdiendo.

A pesar de las medidas de control y protección los acontecimientos y propaganda revolucionarios entran en España, y tienen una distribución relativamente importante por los territorios cercanos a la frontera francesa (País Vasco, Navarra, Alto Aragón y, sobre todo, Cataluña, donde se alienta el fenómeno independentista) y los puertos principales del comercio (Valencia, Málaga y, especialmente, Cádiz).

Los franceses residentes en España estaban, por encima de posicionamientos políticos, deseosos de conocer lo que ocurría en su país de origen y demandaban libros, periódicos, folletos y todo papel escrito que les facilitase dicha información. En la ciudad de Cádiz, miembros de la numerosa colonia francesa se reunían en el antiguo teatro de la ópera, donde «habían formado un círculo conocido por el nombre de la Casa de la Camorra», y allí leían y comentaban las noticias que les llegaban desde Francia, divulgándolas después por la población (8).

Estas actividades llevadas a cabo por un número indeterminado de franceses establecidos en España empezaron a ser mal vistas por las autoridades gubernamentales, a pesar de lo cual se mantuvo, durante los años 1789-90, una política moderada y tolerante hacia los inmigrantes franceses y, en general, hacia todo lo francés, quizás pensando en la solución pacífica del problema y en la salvaguarda de los fuertes intereses económicos comerciales establecidos con Francia. Pero, en junio de 1791 los sucesos se precipitaron en Francia, la huida de Luis XVI a Varennes significaba la ruptura de cualquier compromiso de la monarquía francesa con la Revolución y una radicalización de ésta. Es a partir de este momento cuando el gobierno español decide actuar frontalmente contra los franceses que se encontraban en España. La relación causa-efecto es clarísima. 
El 20 de julio de 1791 se promulga una Real Cédula de S.M. y señores del Consejo, por la que se manda que...

«las justicias hagan matriculas de los extranjeros residentes en estos reinos con distinción de transeúntes y domiciliados, y se establecen las reglas que deberán observarse con unos y otros...» (9).

Dicha Real Cédula, según el preámbulo de la misma, tan sólo pretendía poner en vigor antiguas normas que estipulaban la realización de matrículas, listas, de los extranjeros residentes y transeúntes en España. En las cuales se especificaría, claramente, los correspondientes a cada tipo, para con ello evitar los abusos de los que, alternativamente, hacían uso de los privilegios y derechos concedidos a unos y a otros. Aunque, también, se desliza en el mencionado preámbulo la necesidad de esta orden «para el bien y la tranquilidad del Estado», lo que indica su relación con los temores a la Revolución y, en particular, a las posibles intrigas de la colonia de inmigrantes franceses.

La Real Cédula se componía de tres artículos. El primero de ellos ordenaba la ejecución de las matrículas de extranjeros en todas las localidades de los reinos hispánicos, comenzando por Madrid, sede de la Corte. Esta singularidad expresada con la capitalidad de la monarquía responde a motivos de seguridad nacional, ya que se temía la posible intervención de franceses en atentados contra miembros del gobierno o de la familia real, sobre todo a raíz del intento frustrado de asesinato del que fue víctima Floridablanca el 18 de julio de 1790, en el propio palacio real de Aranjuez, por un francés al que se acusó, aunque nunca se llegó a probar, de ser un «emisario de los <<clubs $>>$ franceses» (10). Los extranjeros, al inscribirse en las matrículas, decidirían si lo hacían en la categoría de avecindados o en la de transeúntes, y aportarían sus datos de filiación, nacionalidad, religión y oficio u ocupación en España.

El artículo segundo establecía lo que las autoridades encargadas de ejecutar las matrículas deberían hacer con los extranjeros, en función de si optaban por avecindarse o considerarse transeúntes.

Los primeros podrían permanecer en España, desempeñando sus actividades laborales y económicas sin ningún tipo de restricciones; pero, para ello, estarían obligados a jurar fidelidad a la religión católica y al soberano español «renunciando a todo fuero de extranjería y a toda relación, unión y dependencia del país en que hayan nacido», es decir, se les exigía la plena nacionalización española, con todas las consecuencias a ella anexas. Afirma Herr que fue el Inquisidor General, Rubín de Cevallos, el que le sugirió a Floridablanca la idea de considerar a todo inmigrante foráneo, con diez años de residencia en el país, súbdito del rey de España, anulándole sus derechos y privilegios como ciudadano extranjero (11). Floridablanca aplicó la idea, ampliando, incluso, su efectividad al no estipular ninguna cortapisa temporal para la nacionalización. El simple juramento, que expresaba la voluntad, sincera o no, de cada individuo, se consideraba suficiente. 
En cuanto a los transeúntes se aplicaba, con todo rigor, el significado de dicho vocablo. Es decir, estos extranjeros se consideraban de tránsito por el país, teniendo su estancia estrictos límites temporales. Igualmente, se prohibía

"...ejercer las artes liberales, ni oficios mecánicos en estos mis reinos sin avecindarse (...); comprendiéndose en esta prohibición la de ser criados y dependientes de vasallos y súbditos míos en estos dominios»

a todos los transeúntes, lo que para muchos venía a significar, si no querían perder sus trabajos o negocios, la obligación de avecindarse y, por lo tanto, de renunciar a su status de extranjería. $Y$ es que, si no se producía el avecindamiento, la normativa era tajante: abandonar la Corte, los que residieran en ella, en quince días y salir del país en un plazo máximo de dos meses. Los que contravinieran estas disposiciones podrían ser expulsados por las autoridades o condenados bien a presidio bien a galeras y, además, ver confiscados sus bienes.

En definitiva, Floridablanca acababa con el teórico problema de los extranjeros de forma drástica, como otras veces en la historia de España, obligándoles a salir del país o compeliéndoles a una nacionalización masiva de dudoso efecto práctico.

Por último, el artículo tercero establecía las pautas que se deberían seguir, a partir de ahora, para la recepción y estancia temporal en territorio español de nuevos extranjeros, incluso los que entraran "con pretexto de refugio, asilo $u$ hospitalidad». Todos, deberían tener en regla sus licencias, expedidas por la Secretaría de Estado, o pasaportes, en virtud de los acuerdos internacionales. En caso contrario, no podrían entrar en España o, a lo sumo, permanecer confinado en una localidad designada por la autoridad mientras se tramitaba la correspondiente licencia, debiendo someterse, en el interín, al rey y leyes españolas. Lo estricto del mencionado confinamiento, junto a la estipulación de las rutas obligatorias que debían tomar los extranjeros en sus desplazamientos, nos indican que la nueva normativa perseguía algo más que conocer el número de inmigrantes foráneos en el país y si éstos eran avecindados o transeúntes. Estaba claro que se pretendía un férreo control sobre los componentes de este grupo, en especial sobre los franceses, para evitar cualquier tipo de propagación de las ideas revolucionarias.

La Real Cédula de 20 de julio de 1791 se envió a las diversas autoridades acompañada de una Instrucción, fechada el 21 de julio, que en un total de 12 artículos explicaba pormenorizadamente la correcta aplicación de la norma, la confección de las matrículas y establecía algunas excepciones. Así, en el artículo 9 se indica que se hagan listas separadas de los maestros y oficiales extranjeros, no católicos, que tuvieran contratas en fábricas de cualquier tipo de manufacturas. Estas matrículas se enviarían al Presidente del Consejo de Castilla, no molestándose a dichos trabajadores extranjeros hasta que se decidiera por la suprema institución gubernamental su destino. El 
mantenimiento de esta mano de obra altamente cualificada en sus puestos fabriles a pesar de su doble carácter de extranjeros no avecindados y no católicos nos muestra hasta qué punto a finales del siglo XVIII se empezaban a imponer en España ciertos aspectos materiales-económicos (apoyo a la producción fabril) sobre los tradicionales como la defensa de la religión. Una orden posterior excluía, asimismo, a los comerciantes ingleses del cumplimiento estricto de la nueva legislación (12), medida que perseguía el mantenimiento del tráfico comercial y que refleja, sin sombras, que la matriculación iba dirigida, principalmente, al control de la colonia francesa.

Tanto la Real Cédula como la Instrucción anexa llegaron a la ciudad de El Puerto de Santa María el 1 de agosto de 1791, iniciando, inmediatamente, el gobernador político-militar de la plaza, D. Claudio Macé, con la cooperación de los regidores locales, el cumplimiento de la misma, concluyendo el trabajo de matriculación de los extranjeros existentes en la ciudad a mediados del mes de septiembre (13). Los resultados de la misma han sido expuestos y comentados por J.J. Iglesias (14), y, resumidos, son los siguientes. Se contabiliza en El Puerto de Santa María un total de 767 emigrantes extranjeros, de los cuales 635 prestaron juramento de fidelidad al rey y, por lo tanto, se consideran avecindados; otros 100 no juraron, por lo que deberían abandonar el territorio español en los plazos prescritos; al igual que otros 32 que dijeron ser transeúntes. Del total mencionado, el 46,5\%, 357 extranjeros, procedían de diversas partes de la península italiana, mayoritariamente de Génova. Los franceses constituían la segunda colonia en importancia numérica, ya que sus 265 componentes representaban el 34,5\% de todos los extranjeros de El Puerto. El restante $19 \%$ lo conformaban emigrantes procedentes de otras seis nacionalidades: malteses $(8,1 \%)$, portugueses $(4,5 \%)$, alemanes $(3,7 \%)$, irlandeses $(1,5 \%)$, flamencos $(0,9 \%)$ e ingleses $(0,3 \%)$. De todas estas colonias fue la francesa la más reacia a acatar el avecindamiento semiobligatorio que se estipula en la normativa. Hasta 94 franceses, el 35,5\% de todos ellos, no ejecutaron el juramento al rey de España, lo que significa el $71 \%$ del total de extranjeros que se negaron a jurar 0 , lo que es lo mismo, a hacer dejación de su fuero de extranjería. Estos porcentajes son bastante aproximados a los obtenidos en el conjunto del territorio nacional, donde los 4.435 franceses que decidieron no avecindarse constituían el $25 \%$ de su colonia y el $68 \%$ de todos los extranjeros que no prestaron el juramento (15). Parece que los temores de las autoridades españolas, al menos por el número de franceses residentes o de paso en España, no eran infundados.

Las trabas puestas para entrar y permanecer en España por la legislación comentada no fueron óbice para la llegada masiva, a partir de 1792, de emigrantes franceses (emigrés) en calidad de «refugiados políticos». Se trata, principalmente, de sacerdotes que huyen de la Revolución, sobre todo a raíz de la orden de la Asamblea Legislativa francesa de 26 de agosto de 1792 relativa a la expulsión de los eclesiásticos que no habían querido jurar la Constitución civil del clero. Por parte española se les atendió correctamente, dándoles hospedaje y manutención, algo en lo que colaboraron activamente sus colegas hispanos. Pero, su excesivo número (16), junto con el peligro de que, intencionada o 
involuntariamente, dieran a conocer los sucesos ocurridos en Francia, que el gobierno español intentaba ocultar, obligó a promulgar una real cédula, en noviembre de 1792, en la que se establecían restricciones al clero emigrado francés en aspectos tales como el lugar de residencia, desplazamientos, actividad pastoral y otros (17).

\section{LA ORDEN DE EXPULSION DE 1793.}

Estaba claro que la nueva legislación que afectaba a los extranjeros residentes en España venía motivada por la situación política interior de Francia y perseguía un estricto control sobre los inmigrantes procedentes de dicho país. Toda la normativa sobre extranjeros promulgada con posterioridad a la orden general de matrícula de 1791 , y al menos hasta los cambios de alianzas internacionales de 1796, tuvo como destinataria, exclusivamente, a la colonia francesa. La sucesión de acontecimientos en el país vecino, arresto de Luis XVI en junio de 1792, la condena a muerte en septiembre de dicho año y su ejecución el 21 de enero de 1793, deterioro sus relaciones con el gobierno español, que comenzó a tomar medidas contra los nacionales e intereses franceses en España.

En esta línea se enmarca la Real Provisión de 4 de marzo de 1793 por la que se ordenaba la expulsión de territorio español de todos los franceses no domiciliados (18). La Real Provisión incluía una Instrucción con 16 artículos que especificaba a las justicias locales la forma en la que debían llevar a cabo el extrañamiento ordenado. Sin pérdida de tiempo intimarían a los franceses no domiciliados, fácilmente conocidos y localizables a través de las matrículas, para que salieran del pueblo hacia la costa o frontera en el plazo máximo de tres días. Cada uno de los franceses expulsos debería llevar un pasaporte en el que, además de su filiación, constaría la ruta que debía seguir y los días con que contaba para ello. Los expulsos no podrían llevar ningún tipo de arma y nunca juntarse en grupos de más de ocho personas. En el lugar de destino, aquel por donde abandonarían suelo español, se les recogería el pasaporte y sus nombres quedarían apuntados en listas que tenían que ser remitida al gobernador del Consejo de Castilla para cotejarlas con las enviadas desde los lugares donde habían estado residiendo.

La orden de expulsión llevaba aparejada el secuestro de los bienes de los mencionados franceses no domiciliados,

«para preservarlos y defenderlos de cualquier insulto, disipación y extravío que pudiera padecer por la celeridad de estas diligencias,(...), manteniéndolos POR AHORA A LEY DE DEPOSITO, para entregarlos después, con las formalidades correspondientes, a las personas y en la forma que se digne S.M. resolver».

Las justicias tan sólo les dejarían la ropa y cierta cantidad de dinero precisas para hacer el viaje de regreso a su país de origen. Esta medida, por su carácter extraordinario, puede ser considerada como de situación prebélica. 
Finalmente, la Real Provisión incluía diversos apartados en los que se especificaba pormenorizadamente, y para evitar excesos y siniestras inteligencias en el cumplimiento de la orden de expulsión, que franceses se consideraban domiciliados o no afectados por la mencionada norma. Estos eran: los naturalizados; los que llevaran residiendo más de diez años y nunca hubieran buscado la protección de los agentes diplomáticos de Francia; los que tuvieran más de seis años de residencia y estuvieran casados con españolas; los hijos de franceses nacidos en España; los arraigados por compra de bienes y posesiones en territorio español; los que hubieran jurado fidelidad al rey y la religión católica en 1791; los eclesiásticos emigrados; los seculares que tuvieran concedido pasaporte de «asilo político»; y los ocupados en fábricas de manufacturas, aunque de éstos últimos se deberían elaborar informes particulares sobre su conducta, en vista de los cuales se dispondría su expulsión o no. Una Real Cédula posterior, del 15 de marzo de 1793, resolvería ciertas dudas que se habían planteado sobre la orden de expulsión.

El cumplimiento de la normativa se realiza en El Puerto de Santa María, por el gobernador político-militar de la localidad, antes de que finalice el mes de marzo. Se puso al día la matrícula de franceses residentes en la ciudad, que ascendían a 256 , casi el mismo número de los existentes en 1791, que recordemos eran 265. Aunque ello no significa una falta de movilidad de los miembros de la colonia francesa, ya que se contabilizan hasta 28 individuos nuevos que han llegado a El Puerto con posterioridad a la realización de la matrícula de 1791, lo que implica, a su vez, que, desde esa fecha, tan sólo se habían marchado 37. La llegada de nuevos inmigrantes franceses, de los que no consta que fuesen peticionarios de asilo, junto con el escaso número de los que se marchan, cuando, no olvidemos, en 1791 hasta 94 galos o rehusaron jurar fidelidad al rey de España o se declararon transeúntes, nos descubren que en 1791 y 1792 la normativa sobre extranjeros, y más concretamente sobre los de origen francés, no tuvo, por falta de voluntad o, como a veces se criticaba por los más intransigentes, por pura connivencia, una correcta aplicación. En ello tuvo que incidir, con toda seguridad, aspectos prácticos como el mantenimiento de la necesaria actividad comercial para los dos países (19).

De los 256 franceses computados en El Puerto desconocemos a cuantos intimó el sr. gobernador para que salieran de España, ya que la lista con sus nombres fue remitida al Capitán General de la zona, no quedando copia en el ayuntamiento (20). Ahora bien, creemos que la autoridad portuense, a pesar de las advertencias contenidas en la Real Cédula de 4 de marzo, actuó con exceso de celo, tal como lo demuestra el hecho de que hasta 74 individuos de origen francés se vieron obligados a recurrir la orden de expulsión, aportando documentos que avalaban su avecindamiento, logrando, la mayoría de ellos, un dictamen favorable a su pretensión de permanecer en España. Al final el número de franceses expulsos fue, aproximadamente de 40 , no pudiéndose concretar la cifra exacta ya que aparecen varias relaciones que aportan datos contradictorios sobre la ejecución efectiva de la orden en El Puerto de Santa María. 


\section{LA JUNTA DE REPRESALIAS.}

Las relaciones entre España y la Francia revolucionaria se volvieron extremadamente tensas tras el ajusticiamiento de Luis XVI. La monarquía española empezó a tomar medidas contra los intereses franceses, tales como el decreto de expulsión que acabamos de comentar. Como resultado de todo ello el gobierno francés declaró la guerra a España el 7 de marzo de 1793, y la monarquía española a Francia por decreto de 25 de marzo de 1793 (21). La nueva situación de guerra abierta va a permitir al gobierno español apoderarse de los bienes secuestrados, hasta ese momento en calidad de ley de depósito, a los franceses expulsados en aplicación de las Reales Provisiones de 4 y 15 de marzo. La excusa que se daba para convertir el secuestro preventivo en embargo efectivo era la de la necesidad de indemnizar con el valor de dichos bienes

«a los cuerpos y casas comerciantes, y a los particulares vasallos que hayan padecido pérdidas o cualquier especie de daño por los insultos, agresión, irrupción de tierra y mar, y por la falta de administrarles justicia la Nación francesa o los que han tomado su nombre».

Para todo lo concerniente a la administración y-o venta de los bienes embargados, las reclamaciones que se plantearan por familiares o apoderados de los franceses expulsos y la resolución de los expedientes en demanda de las apuntadas indemnizaciones, se creaba, por Real Cédula de 6 de junio de 1793, un tribunal especial con el nombre de Junta de Represalias (22). Este tribunal, de cuya tipología existían repetidos ejemplares en el siglo próximo pasado, estaría compuesto por seis vocales, de los distintos consejos reales, un fiscal y un secretario. Los comienzos de sus trabajos no fueron fáciles, debido a que había un cuerpo legal amplio, variado y, a veces contradictorio, sobre los temas de compentecia de la Junta de Represalias. A ello se sumo el sinnúmero de errores cometidos por las autoridades locales al incoar los expedientes y la avalancha de pedimentos y reclamaciones hechas por los distintos afectados. Para salir de esta confusión y marcar las pautas generales que deberían aplicarse en la resolución, en sus sucesivas fases, de estos asuntos, la Junta de Represalias formó una prolija Instrucción, con un total de 36 artículos, que fue promulgada el 16 de agosto de 1793 (23).

La Instrucción tardó un mes en llegar a El Puerto de Santa María, como lo prueba un auto del gobernador de la localidad emitido el 17 de septiembre, en el cual acusaba su recibo y convocaba a los apoderados de los franceses expulsos o, en su defecto, al síndico procurador general de la ciudad, para revisar los avalúos de los bienes, enajenados o en existencia, paso previo a la remisión de las cuentas a las autoridades superiores. Este trámite nos ha permitido conocer la tipología y montante de los bienes embargados a los franceses expulsados en El Puerto. De todos los expulsos, que recordemos fueron en torno a 40 , solamente a 9 se les pudo secuestrar, paso previo al embargo, sus posesiones. Los restantes, según se desprende de la documentación, o carecían de bienes o 
no se les pudo probar que los poseyeran; alguno, incluso, logró ponerlos a salvo antes de que se le notificara la orden de expulsión.

En el cuadro 1, que incluimos a continuación, podemos ver los nombres de los 9 franceses expulsos con bienes embargados. Asimismo, el valor, en reales de vellón, de dichas posesiones, subdivididas en bienes inmuebles, mercancías y deudas a favor. Al montante obtenido en cada caso se le descuentan los gastos causados por la custodia y venta de los bienes, las deudas en contra que se abonan por las autoridades competentes y los débitos reclamados pero pendientes de satisfacer por múltiples motivos, generalmente la falta de documentación probatoria.

Las nueve personas embargadas eran comerciantes: tres de ropas (los srs. Domec, Lacomme y Casaux), uno de vinos (el sr. Rance), uno de maderas (el sr. Macenod), uno de frutos secos (el sr. Larrard), y los otros tres (los srs. Lahaa, Manota y Leboubetel) no llega a especificarse en los expedientes. El valor de los bienes embargados no supera los 100.000 reales en cuatro casos; en otros tres se sitúa entre los 100.000 y 200.000 reales; mientras que en los dos restantes se eleva por encima del millón de reales. Nos estamos refiriendo a la compañía de D. Diego Domec y hermanos, a la que se le embarga por valor de 1.283.348 reales; y a D. Diego Lacomme cuyos bienes secuestrados valían 1.209.655 reales.

El dato que más llama la atención, no tanto si tenemos en cuenta que se trata de comerciantes al por mayor de ámbito internacional, es la presencia de créditos y deudas diversas a favor y en contra. Los primeros, por valor de 2.548 .006 reales, representan el $81,4 \%$ de la cantidad total generada por los expedientes de embargo. Mientras que las deudas en contra, abonadas o por pagar, ascienden a 1.130.021 reales, o lo que es lo mismo, el $36,1 \%$ del valor de todos los bienes embargados. 


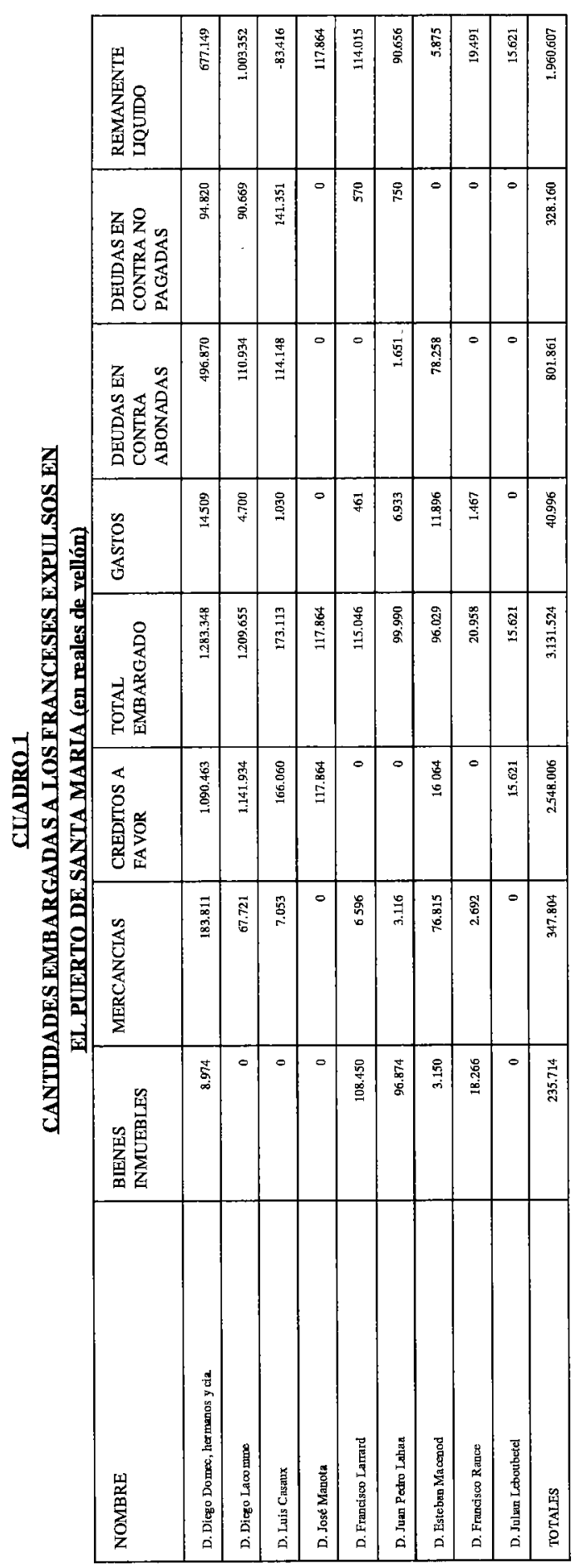


Los bienes inmuebles son mínimos, cuatro casas, dos de ellas pequeñas, y dos parcelas de viña de escasa extensión, por lo que su valor apenas representa el 7,5\% de todo lo embargado. Por su parte, la venta de las distintas mercancías ocupadas proporcionó el $11,1 \%$, porcentaje mínimo si se tienen en cuenta los montantes que conocemos de los créditos a favor y en contra de dichos comerciantes. Nos encontramos ante negocios donde abunda el papel y en los que el riesgo, el peligro de quiebra, está siempre presente.

La ejecución global de todos los embargos, el peritaje de los bienes, los trámites administrativos, etc, generaron unos gastos, difíciles de individualizar por expedientes concretos, que ascendieron a la cantidad de 15.680 reales. De éstos, la mayor parte, 6.262 reales, se los embolsó el único escribano que se encargó de la totalidad del papeleo. Por detrás, estarían el alguacil mayor de la localidad, que obtuvo 3.632 reales, y el maestro mayor de carpintería, al que se le abonaron 1.467 reales. Otras 23 personas recibieron cantidades que oscilaban entre los 25 y 700 reales. Todos ellos fueron los verdaderos beneficiarios de la expulsión de los franceses y el embargo de sus bienes.

\section{EL INTERNAMIENTO DE 1794.}

Si las últimas disposiciones comentadas incidieron, exclusivamente, sobre los franceses declarados transeúntes, el desarrollo bélico a partir de 1793 va a dar lugar a la adopción de medidas que afectan a los franceses domiciliados. Así, una Real Cédula de 25 de septiembre de 1794 ordenaba que cualquier francés, domiciliado o emigrado, que viviera en localidades que se hallaran ubicadas «a menor distancia de veinte leguas de la frontera de Francia y costas marítimas de estos mis reinos», fuera intimada para que en el plazo máximo de ocho días se desplazara a localidades del interior, que no fueran la corte ni los sitios reales, situadas a más de veinte leguas de las mencionadas fronteras y costas (24).

La orden era justificada por el monarca, en el contexto de la guerra contra la Francia revolucionaria, ante los muchos memoriales y representaciones que se le remitían quejándose de las actitudes sospechosas mantenidas por franceses, residentes en España, que mostraban «cierta inclinación a las máximas, espíritu $y$ designios de los revolucionarios». Por todo ello, y para "precaver todo riesgo a mis amados vasallos», ordenaba el internamiento forzoso. Ahora bien, éste no debía ser considerado como "pena de un delito», sino, tan sólo, como «una providencia económica de precaución conveniente y aún necesaria en las actuales circunstancias». Las justicias locales, además de señalar el internamiento, deberían de contabilizar a los internados, fijar las rutas del traslado y evitar una concentración excesiva de franceses en una misma población. Aquéllos que tuvieran la obligación de internarse y desobedecieran la normativa se les impondría una multa de 100 ducados, cantidad que dudo tuvieran muchos de los franceses domiciliados en España. 
Esta última Real Cédula es, extrañamente, la única de las que hemos nombrado de la que no encontramos en el archivo municipal de El Puerto su expediente de cumplimiento. Hubiera sido interesante comprobar en él hasta que punto la colonia francesa 0 , en concreto, algunos de sus componentes eran protegidos por las autoridades locales, permitiéndoles permanecer en su lugar de residencia. Tenemos constancia de peticiones formuladas por franceses al ayuntamiento portuense solicitando, por diversos motivos, no abandonar la localidad, pero desconocemos las respuestas que se les dieron. Por otras fuentes documentales se detecta la permanencia de algunos franceses en El Puerto, contraviniendo la orden, sin que se tomen medidas disciplinarías contra ellos (25).

La permanencia de franceses en localidades costeras, como El Puerto de Santa María, era justificada por éstos apelando a su condición de súbditos del rey de España, ya que, recordemos, desde 1791 todo extranjero, no transeúnte, que quisiera permanecer en territorio español estaba obligado a renunciar a su fuero de extranjería y jurar fidelidad al soberano y leyes de España, lo que, prácticamente, equivalía a una naturalización. La gran contradicción de la Real Cédula de 25 de septiembre de 1794 estribaba precisamente en esta cuestión. Se trataba como extranjeros a unos franceses avecindados a los que tres años antes se les había casi obligado a convertirse en súbditos de S.M. católica. Esta contradicción prueba que la normativa de 1791 no perseguía ningún tipo de asimilación de los inmigrantes extranjeros en la sociedad española, sino tan sólo, y como ya hemos apuntado reiteradamente, su control en general y el específico de la colonia francesa.

Los cambios en la política internacional a partir de 1795, con la nueva alianza hispano-gala, van a atenuar las medidas tomadas contra los franceses residentes en suelo español. Estos dejan de ser, al menos a los ojos del gobierno central, sospechosos de revolucionarios para convertirse en potenciales aliados. Años de tranquilidad se abrían para la colonia francesa, que volverían a quebrarse a raíz de la Guerra de la Independencia.

A lo largo de las páginas precedentes hemos podido comprobar como el poder del Estado, ya ciertamente potente a finales del siglo XVIII, se deja notar con fuerza sobre un grupo marginal: los inmigrantes. El pretexto o la justificación para actuar sobre ellos lo proporciona la situación política interior de Francia, conmovida por los sucesos y los excesos revolucionarios. A ello se suma el temor sobredimensionado de las autoridades y la desconfianza e incomprensión del pueblo español, o de partes significativas de él, hacia ese contingente de extranjeros que, mayoritariamente, buscaban en España una subsistencia que no entiende de límites fronterizos. La actuación estatal, solicitada en ocasiones por la población, se reduce a la aplicación de una normativa que comienzan siendo de inspección y control, las matrículas, para derivar en medidas de carácter represivo: trabas a las actividades desarrolladas por los extranjeros en España, incluidas las laborales; exigencias veladas de 
dejación de los derechos de extranjería; expulsión del país, si no se renuncia a tales derechos; secuestro y embargo de bienes; obligación de internamiento; etc.

Estas conclusiones pueden estar impregnadas de cierto presentismo, influenciadas por los efectos de un fenómeno, la discriminación hacia los inmigrantes, que se considera muy de nuestra época contemporánea y de actualidad informativa. Pero, no olvidemos que el historiador trabaja el pasado inmerso en el presente, y con la obligación de intentar comprenderlo y explicarlo: Presentar los errores del pasado, especialmente los provocados por la intolerancia, en el caso concreto que nos ocupa la xenofobia, tiene por objeto, al menos mínimo, provocar a la reflexión y, si es posible, incitar a buscar soluciones.

Las líneas finales las quiero dedicar al prof. José Luis Millán Chivite, a cuya memoria se dedica este número de la revista Trocadero, él fue ejemplo de tolerancia y de buena persona.

\section{NOTAS.}

(1) Los principales estudios sobre los extranjeros en el siglo XVII son los de DOMÍNGUEZ ORTIZ, A.: Los extranjeros en la vida española durante el siglo XVII, Madrid, 1960; y NADAL, J. y GIRALT, E.: La population catalane de 1553 à 1717. L inmigration française, París, 1960.

(2) Sobre Cataluña la obra de NADAL y GIRALT ya mencionada y MOREUREY, E.: Els inmigrants francesos a Barcelona (ss. XVI-XVIII), Barcelona, 1950. Un ejemplo de la zona aragonesa en SALAS AUSENS, J.A.: «La inmigración francesa a Barbastro en los siglos XVI y XVI», en Estudios/77, Zaragoza, 1977, pp. 41-84. En Andalucía, CORONAS TEJADA, L.: «La inmigración francesa en las ciudades de Jaén y Ubeda en la segunda mitad del siglo XVIII", en Actas del II Coloquio de Historia de Andalucía. Andalucía Moderna, I, Córdoba, 1983, pp. 35-54; PONSOT, P.: «Les françaises a Cordove en 1791-1793», Melanges de la Casa de Velázquez, XV, 1979, pp. 503-507; PONSOT, P.: «Emigrantes franceses en Andalucía: ejemplo de Osuna (1791)», Archivo hispalense, LXII, 189, 1979, pp. 107-115; y VILLAR GARCIA, M BEGOÑA: Los extranjeros en Málaga en el siglo XVIII, Córdoba, 1982.

(3) Los propios títulos de los trabajos reseñados en la nota 2 muestran claramente esta preferencia por los inmigrantes franceses.

(4) Hipótesis recogida en el manual, ANES, G.: El Antiguo Régimen: Los Borbones, Madrid, 1978, pp. 138-139.

(5) Sobre los extranjeros en la zona gaditana antes del siglo XVIII pueden consultarse las obras de SANCHO DE SOPRANIS, H.: «Los genoveses en la región gaditano-xericiense de 1460 a 1800», Hispania, VIII, 1948, pp. 255-402; y «Extranjeros en Cádiz en los siglos XVI y XVII», Estudios de Historia Social 
de España, IV, 1960; EVERAERT, J.: «Le commerce colonial de la nation flemande a Cadix sous Charles II (1670-1700)», Anuario de Estudios Americanos, XXVIII, 1971. Y en el XVIII, COLLADO VILLALTA, P.: «El impacto americano en la bahía: la inmigración extranjera a Cádiz, 1709-1819», I Jornadas de Andalucía y América, Sevilla, 1976, pp. 49-73; CRUZ BELTRAN, J.M.: «Noticias sobre la inmigración extranjera en la bahía gaditana: el caso de Puerto Real (1780-1850)», Gades, 9, 1982, pp. 91-99; SANCHEZ, R.: «Los malteses en El Puerto del siglo XVIII: su pleito con los mercaderes de vareo», Revista de Historia de El Puerto, 1, 1988, pp. 79-93; IGLESIAS, J.J.: Una ciudad mercantil en el siglo XVIII: El Puerto de Santa María, Sevilla, 1991, pp. 493-529; y LOZANO, M.D.: «Aproximación al estudio de los extranjeros en Jerez en el tránsito del XVIII al XIX», Trocadero, 2, 1990, pp. 135-170.

(6) Especialmente en lo relacionado con la llegada de comerciantes extranjeros, COLLADO, P.: «En torno a los origenes del monopolio comercial gaditano: mercaderes extranjeros y cambio económico del área sevillana a la bahía de Cádiz en la segunda mitad del siglo XVII», Actas II Coloquios de Historia de Andalucía. Andalucía Moderna, I, Córdoba, 1983, pp. 603-616; y BUSTOS RODRIGUEZ, M.: Los comerciantes de la Carrera de Indias en el Cádiz del siglo XVIII (1713-1775), Cádiz, 1995, en especial las pp. 202-238.

(7) HERR, R.: España y la revolución del siglo XVIII, Madrid, 1988, p. 212; y ANES, G.: Op. cit., p. 419.

(8) Así lo informaba el comisario de la Inquisición en Cádiz al inquisidor general. A.H.N., Inquisición, leg. 4436, exp. 12, citado por HERR, R.: Op. cit., p. 201. Ver también, ENCISO RECIO, L.M.: «Actividades de los franceses en Cádiz, 1789-1790», Hispania, XIX, 1959, pp. 251-286.

(9) Real Cédula de S.M. y Consejo de 20-7-1791. Archivo Municipal de El Puerto de Santa María (A.M.P.S.M.), leg. 1617.

(10) HERR, R.: Op. cit., p. 205.

(11) HERR, R.: Op. cit., p. 212.

(12) Citada por HERR, R.: Op. cit., p. 212.

(13) Todo el expediente, que incluye la matrícula dividida por barrios, se encuentra en A.M.P.S.M., leg. 1619.

(14) IGLESIAS RODRIGUEZ, Juan José: Op. cit., pp. 504-506.

(15) Las cifras totales nos la ofrece DOMÍNGUEZ ORTIZ, A.: Sociedad y Estado en el siglo XVIII español, Barcelona, 1976, p. 507. 
(16) HERR, R.: Op. cit., p. 248, comenta la llegada a España de más de 6.000 clérigos hasta el mes de abril de 1793.

(17) Real Cédula de S.M. y señores del Consejo por la cual se establecen las reglas que se han de observar en cuanto al modo de permitir la entrada de eclesiásticos franceses en estos Reinos, y su permanencia en ellos, San Lorenzo de El Escorial, 22 de noviembre de 1792.

(18) Real Provisión de los señores del Consejo, en que se manda guardar y cumplir la resolución tomada por S.M. para el extrañamiento de los franceses no domiciliados en estos reinos, Madrid, 4-3-1793. Un ejemplar en A.M.P.S.M., leg. 1646-A.

(19) SEE, Enrique: «Notas sobre el comercio francés en Cádiz y particularmente sobre el comercio de telas bretonas en el siglo XVIII», Anuario de Historia del Derecho español, $\Pi, 1925$, p. 194, señala como el periodo comprendido entre septiembre de 1791 y septiembre de 1792 fue bastante intenso en la relaciones comerciales hispano-francesas.

(20) Así lo especifica el escribano municipal encargado del asunto. El expediente completo sobre la aplicación de esta orden de expulsión en A.M.P.S.M., leg. 1646-A.

(21) Sobre esta guerra, llamada de la Convención, ver el trabajo de AYMES, J.R.: La guerra de España contra la Revolución Francesa (1793-1795), Alicante, 1991.

(22) Real Cédula de S.M. y señores del Consejo, por la cual se crea, erige y autoriza un Tribunal con la denominación de Junta de Represalias, para que única y privativamente conozca de todo lo concerniente a secuestro de los bienes de los franceses expulsos, indemnizaciones que con su valor se deban hacer a los vasallos y súbditos de estos reinos, y demás contenido en los capítulos insertos, Aranjuez, 6 de junio de 1793. Una copia en A.M.P.S.M., leg. 1617.

(23) Real Cédula de S.M. por la que se manda guardar la instrucción en ella inserta, formada por el tribunal de la Real Junta de Represalias, para gobierno de las justicias del reino en la expedición de las causas de los secuestros de bienes ocupados a los franceses expulsos, San Idefonso, 16 de agosto de 1793. Una copia en A.M.P.S.M., leg. 1617.

(24) Real Cédula de S.M. y señores del Consejo por la cual se manda que todos los franceses domiciliados y emigrados de cualquier clase y estado que sean residentes en los puertos marítimos y pueblos inmediatos a ellos y a la frontera de Francia, se internen en el reino a veinte leguas de los mismos puertos y frontera, San Ildefonso, 25 de septiembre de 1794. Un ejemplar en A.M.P.S.M., leg. 1646-B. 
(25) LOZANO, Ma Dolores: Op. cit., pp. 145-146, aporta algunos casos de franceses residentes en Jerez de la Frontera que soslayan el cumplimiento de la Real Cédula. 